\title{
TOURISM AND CHANGING PATTERN OF LIVLIHOOD
}

\author{
Dilli R. Prasai \\ Tribhuvan University \\ E-mail: dilliprasai@yahoo.com
}

\begin{abstract}
Barahachhatra have got good food, shelter, entertainment, education and others through tourism and they have got standard life and tourism industry is being own of the great for them to change their lifestyle positively.Tourism industry is the employment generating industry in the context of our country. It gives employment for skilled and unskilled people. The employment opportunity has significantly increased in Barahachhatra with the development of tourism business especially by hotel industries and then hotel owner and employees have positively changed their lifestyle by the help of tourism.
\end{abstract}

Key words: Tourism, folk tradition, gastronomy, Anthropology, rafting

\section{Background}

The word 'Tourism' has been originated from French word 'tourism' which means movement of human beings from one place to another for leisure, holiday making or for different purposes. Various scholars have defined tourism in their own words and the definition has changed over years implying changes in scope and trend.

\section{Types of Tourism}


- Adventure Tourism: The segment of tourism consisting of programs and activities with a connotation of challenge, expeditions full of surprises, most often for adults, involving daring journeys and the unexpected for examples: climbing, caving, jeep -safari is known Adventure Tourism.

- Pleasure Tourism: The segment of tourism consisting of programs and activities developed to improve or balance the physical or spiritual condition of an individual or group of persons. Examples: yoga workshop, detoxification clinics, spas.

- Culture Tourism : The segment of tourism consisting of programs aimed as participants interested in learning the customs of a certain people or region. Examples: dance, folk tradition, gastronomy.

- Religious Tourism: The segment of tourism consisting of programs aimed at participants visiting sites of religious importance to their practicing religion. Examples: temples, mosques, monasteries, places of religious importance etc.

- Sports Tourism: The segment of tourism is consisting of programs and activities for the specific purposes of promoting the practice of sports by amateurs and professionals. Examples: mountaineering, golf, diving, fishing.

- Study Tourism: The segment of tourism consisting of programs and activities for learning, training of increasing knowledge on site, involving students and teachers with local professionals. Examples: anthropology, botany, cookery, languages, photography, zoology. 
- Incentive Tourism: The segment of tourism is consisting of programs and activities for companies or organizations, for the purpose of motivating or rewarding officials or terms to achieve production or quality targets. Examples: river and sea cruises, jeep safaris.

- Research Tourism: The segment of tourism dealing with trips and expeditions for survey and/or study, developed by institutions or professionals interested in specific topics. Examples: Anthropology, Archaeology, Botany, Environmental impact.

- Professional Tourism: The segment of tourism consisting of programs and activities allowing professionals to have direct contact on site with the fields in which they are involved and where they can increase or exchange knowledge with other professionals. Examples: agriculture, anthropology, botany, geology.

\section{Tourism in Nepal}

Nepal is a popular destination to the outside world particularly for the people of neighboring countries like India and China. It is said that Gautam Buddha and his follower have visited various and entered into matrimonial relation. During this period many foreigners from the neighboring countries had paid their visit to Nepal for different purpose such as socio-political and commercial level then the history of Nepalese tourism has been started. Tourism has been competitively developing in the world, and due to specific natural and cultural heritages, there is a great possibility of tourism industry in Nepal. Hence, in other to increase national production and income to expand the earning of foreign currencies to create opportunities for employment by decreasing regional imbalance and to develop the image of 
Nepal in international community having developed and expanded tourism industry (Bhattarai, $2002: 43-44$ ).

Nepal still has a long way to go in restructuring its political system and in acceleration in the pace of its economic growth and human development. World Human Development Report-2004 shows its rank $140^{\text {th }}$ out of 177 countries which is the indication of improvement from the last year's report in which it was in $143^{\text {rd }}$ positions among 175 countries. So tourism can be the best industry for the economic growth and human development in the country like Nepal.

\section{Tourism and its Significance}

Tourism is an ancient phenomenon. At present tourism is recognized as one of the chief industries throughout the world. Every country tries to get benefit from tourism. In many countries, it is one of the major sources of foreign exchange and employment. Besides this, tourism has also encouraged the growth of an international society of social and cultural attributes to much extent.

Tourism comprises the activities of persons travelling to and staying in place outside their usual environment for not more than one consecutive year for leisure, business and other purposes not related to the exercise of an activity remunerated from within the place visited.

Tourism is the major component of modernization and globalization. The WTO defines the sustainability tourism development as a development that needs of the present tourists and host regions while protecting and providing opportunity for the future. It is envisaged as leading to management of all resources in such a way the economic, social and aesthetic needs can be fulfilled while maintaining 
cultural integrity, essential ecological process, and bio-logical diversity and life support systems. The depiction also highlights the importance of social-cultural values equally with economic one.

Travel and tourism is the world's biggest industry in terms of global GDP and employment. It was estimated that tourism in an average year account for trillions worth of economic activity or about $10 \%$ of the world's GDP, and employing millions of people.

Tourism and Economics cannot be separated. Governments in many countries have realized this and today are aware of this significant phenomena and the role that tourism plays as a catalyst for economic growth. This industry not only opens up new job opportunities, but can also enrich the livelihood of the residents and the communities within a country. Tourism provides the basis upon which communities can renew their pride the heritage and upgrade their quality of life.

\section{Issues and Discussion with Research Question}

As growth of tourism and social problems are two sides of a coin, the development of tourism tends to disrupt the traditional activities of the local population. In such a situation, the natives gradually leave their traditions, customs, manners, habits norms values and ethics. In the long run this will create a big problem in the traditional society. If cultures transform in this way, destination gradually loses its importance and there would have been no sustainability in the field of tourism. So the locals of tourists' destinations should have enough awareness about the various impacts of tourism. For the effective performance of the study and to state the 
findings in concrete and precise for important research questions have been structured as below:

- Why do tourists visit a destination?

- Do the hosts and tourists satisfy with each other?

- Is tourism an agent of socio-cultural change?

- How tourism can be improved?

Hence, this study tries to analyze the status of tourism in Barahachhatra area, shows development which has taken place so far and identify the problems, prospects as well as it also recommends some suggestions for further development.

\section{Objectives of the study}

The general objective of the study is to analyze the socio-cultural influences through Tourism. The specific objectives are listed as below:

- To find out the motivation of tourists.

- To find out the socio-cultural change through tourism

- To explore impacts, problems and prospects in the field of development of tourism in the study area.

\section{Use of Research Tools}

Questionnaire: For the collection of the primary data structure and semi-structure schedule has been prepared. It is related with the objectives of the study.

Key informant Interview: To generate accurate primary data, key-information was involved by the semi or unstructured interview method. The interviews have been taken as cross checking for data obtained from the questionnaire. The informants were interviewed on the people who were directly involved in the riverside area and it focused the environmental impact to their health. 
Field visit and observation: It is equally important to have an observation of the respondents' activities to generate the authentic data about the question which were not answered by them. They could be shy, illiterate or sometime they exaggerate the stories. So information was collected and maintained in diary. Thus observation also helped the searcher to catch their natural activities in sights.

Focus Group Discussion : Focus group discussions were held among those who are the real stakeholders of tourism in Barahachhatra. These were hoteliers, restaurateurs, tourists and employees. Locals were also imparted in FGD. Local people who facing and their solution to lift their standard of living for environmental conservation and retaining the beauty the area possesses, local people should be aware and focus group discussion fulfills this category. It also helped to provide the required data.

\section{Findings}

The key informants i.e. tourists, stakeholder (shopkeepers), locals and the government officials have made mixed commentaries on the tourism activities on the Barahachhatra.

Most shopkeepers are Nepalese, which is $63.64 \%$ and $63.63 \%$ of shopkeepers are married. $45.45 \%$ are in the age group between 30 to 50 years of age. $36.36 \%$ stakeholders are under SLC and above SLC, this shows that educated people are also involve in tourism business. Most of the stakeholders are Hindu, they are $72.73 \%$. Most experienced stakeholder thought to continue their business. $63.63 \%$ of the stakeholders have the experienced more than 5 years. Economic factors are the major cause to continue the business, such stakeholders are $72.73 \%$. Peak season of their business are spring and summer 
equal $36.36 \%$ respondents said that spring and summer seasons are good for business. Majority of the respondents earn between 10,000 and 25,000 which was followed by $27.27 \%$ of respondent who earn between 25,000 to 50,000 thousands and above 50 thousands. $45.45 \%$ of the respondent have continue this business for future but only 2 respondent want to abundant this business. The security system of the study area is very good. majority respondent (54.55\%) are the very confidence with the security system of the study. 12 stakeholders can speak 2 languages whereas 6 respondents can speak more than two languages. $54.55 \%$ of stakeholders serve 1 to 20 customers regularly and their favorite customers are European. Local authorities of Barahachhatra are very helpful. They are serious to the problems of shopkeeper. 7(63.64\%) respondents were grateful for the shopkeepers. Tourist asked for the drugs or prostitutes to the 6 shopkeepers, which is $27.27 \%$ of the respondent.

Similarly $75 \%$ locals are Nepalese; most of them are in nuclear family i.e. $66.67 \%$. Half of the locals are $72.73 \%$ of the respondents are Chhetry/Brahman, $18.18 \%$ Janajati. 8 (33.33\%) of the locals have passed SLC and 9.9\% of locals are illiterate and more than higher education. Majority of the locals have followed to the Hindu religion. $9(75 \%)$ respondents are Hindus where $81.82 \%$ of locals are male and $18.18 \%$ are female. $45.45 \%$ are age of between 30 to 50 years and $27.27 \%$ are above 50 years.

In tourists $63.64 \%$ and $36.36 \%$ are male and female respectively. $18.18 \%, 54.55 \%$ and $27.27 \%$ are in below 20 , 20-50 and 50 in age. Average income per month of locals is 10 to 25 thousands followed by $41.67 \%$. $27.27 \%$ of the locals have said the tourists' activities of Barahachhatra are responsible to increase the prostitution. The others said 'No'. 
Tourists arrive in the period of local festivals also involve in the festivals. $75 \%$ of the local have said that tourism can change the society/culture.

Most of tourists are come here for the purpose of adventure. This shows that mountains climbing, , rafting are the major adventure sectors of Nepal. $27.27 \%$ of the tourists come here for adventure. Most of the tourists live in Nepal between 5 to 15 days which is followed by $27.27 \%$ of tourist to the duration of more than 15 days. Service available in the study area is the major factor to come the tourists in Barahachhatra. $45.45 \%$ tourists come here because of the service available whereas environment of site is $27.27 \%$ and hospitality of locals and stakeholders are $18.18 \%$.

\section{Conclusion}

Barahachhatra became famous as a tourist area since the historically. Ever since that time it has been one of the major attractions of the eastern region. Most of the tourists who came to eastern Nepal and have time to do sightseeing go to Barahachhatra. Due to its popularity among tourists, tourist related shops and restaurants slowly started to crop up. Now, we can hardly find another place in Nepal which has such a dense concentration of tourist related shops and restaurants. Tourism can be fruitful for the nation when there is peace, security and proper management among different sectors. Tourism is an industry like other industries. It is the basic industries for development of the fundamental things of Nepalese economy. The aim of bringing 5.5 lakh tourist per annual is very weak point today. Tourism sector is remained confusion position. It is the best income earning sectors so that priority should be given on it. If the tourism industry is destroyed the country will be suffered by poverty and 
disorder. Now it has many problems such as lack of sufficient airline, few tourism sports and services, unreliable communication, dual economy, improper banking system, poor institutions, unclear rule and regulation etc which can be decreased adopting the best polices and implementing them. Tourism was flourished after unification, many plans, polices; legal acts were formed to develop the tourism sector. Many forms of the tourism have developed and many programmes on the tourism were celebrated to promote tourism industries.

When asked, all the shopkeepers and restaurants and other stakeholders said that there were peace in the country, there would definitely be an increase in the arrivals of quality tourists. This would not only make it easier for them to do business, they would not have to even think of looking for an alternatives source of income, because that depended on the arrival of tourists, but it would also greatly benefit the economy of the country. This proves that perceptions of political instability and safety are a prerequisite for tourist visit. Violent protests, social unrest, civil war, terrorist actions, the perceived violations of human rights, or even the mere treat of these activities can all serve to cause tourists to alter their travel behavior.

In the case of lacking food, clothing, shelter, entertainment, health, education and other things, the lifestyle is considered poor, whereas hotels owners and employees on Barahachhatra have got good food, shelter, entertainment, education and others through tourism and they have got standard life and tourism industry is being own of the great for them to change their lifestyle positively.

Tourism industry is the employment generating industry in the context of our country. It gives employment for 
skilled and unskilled people. The employment opportunity has significantly increased in Barahachhatra with the development of tourism business especially by hotel industries and then hotel owner and employees have positively changed their lifestyle by the help of tourism.

Finally, through the finding, it can be concluded that education helps to fulfill and use the hidden talents and abilities of every individuals. Thus, the concerned authority should arrange for the suitable training on salesmanship; limited areas should be allotted for them

to do their business in Barahachhatra in order to avoid unwanted hitches and troubles against foreign tourists.

\section{References}

Bhatia, A. K. (2001). International tourism management, New Delhi: Sterling.

Cohen, E. (1984). The sociology of tourism: Approaches, issues and findings, London: Heinemann Book education

Dahal et.al. (2069). Sapta-Koshi saroka abhiyan Nepal, Makalu Publication Itahari

DDC, Sunsari (2068). Sunsati district profile, Sunsari Publication, Ithari

Herbert, S (1995). Heritage tourism and society, New Delhi: Wishwa publication

Kunwar R.R. (2002). Anthropology of tourism, New Delhi: Nepal Adroit Publishers

Shrestha, H. P. (2002). Tourism in Nepal: Marketing challenges. New Hira Publication, Kathmandu.

Smith (1989). Hosts \& guests: The anthropology of tourism, New Delhi, Sage Publication 
Steve, M. (2070). Nepal and Nepalese Hospitality: Article review, Illinois University, Southern California, Pittenberge Institute USA. 